\title{
Investigating the Burden of Mental Distress Among Nurses at A Provincial COVID-19 Referral Hospital In Indonesia: A Cross-Sectional Study
}

Marthoenis Marthoenis

Syiah Kuala University

Maskur Maskur

Zainoel Abidin General Hospital, Banda Aceh

Liza Fathiariani

Aceh Psychiatric Hospital, Banda Aceh

Jacqueline Nassimbwa ( $\square$ nassimbwajacqueline@gmail.com )

Health Plus Development Communication

\section{Research Article}

Keywords: Prevalence, Financial, Depression, Anxiety, Stress, Nurse, COVID-19

Posted Date: February 24th, 2021

DOl: https://doi.org/10.21203/rs.3.rs-221595/v1

License: (c) (i) This work is licensed under a Creative Commons Attribution 4.0 International License. Read Full License 


\section{Abstract}

Background: The current outbreak of COVID-19 pandemic distorts not only the physical, but also mental and psychological condition of healthcare providers, especially the nurses who directly working with the COVID-19 patients. This study aims to investigate the prevalence and risk factors of depression, anxiety and stress among nurses working in a COVID-19 referral hospital in Indonesia.

Methods: A cross-sectional study was conducted. A self-administered questionnaire, DASS21, along with the demographic questions was used to screen the presence of psychological problems and their associated factors.

Results: the prevalence of moderate to extremely severe depression, anxiety and stress was $8.7 \%, 20.7 \%$ and $5.8 \%$, respectively. The prevalence rate was significantly higher among those with financial hardship during the COVID-19 pandemic, with $10.5 \%, 23.5 \%$ and $8.1 \%$ for depression, anxiety and anxiety $(P<.05)$, respectively. Regression analysis confirmed that these mental problems were associated with the experience of social rejection, either by family or neighbor, because they were working in the hospital during the pandemic.

Conclusions: The financial hardship experienced by the nurses during disease pandemic increases their burden of mental illness therefore, providing the financial subsidiary might reduce their financial uncertainty. Furthermore, the motivation to have a positive attitude toward the pandemic, promotion of healthy behavior such as the use of face mask and the provision of sufficient information on the diseases, may help them properly manage their mental distress.

\section{Background}

Globally, the spread of the corona virus disease (COVID-19) causes substantial health burdens and has major implications on the mental health of the public. Frontline healthcare workers, especially the nurses working with COVID-19 patients are at a higher risk of infection and disease, and this increases their vulnerability to psychological distress. Earlier studies reveal poor sleep quality (1), depression, anxiety, stress $(2,3)$, Post Traumatic Stress Disorder and burnout (4), among these frontline cadres. A recent Systematic Review and Meta-analysis of 93 studies published between January and September 2020 (5) shows that approximately one-third of nurses working during the COVID-19pandemic suffered from psychological symptoms. The study specifically discovered a pooled prevalence rate of $35 \%, 37 \%$ and $43 \%$ for depression, anxiety and stress, respectively.

Mental distress among nurses have been linked with various risk factors and comorbidities. Depression, for example is positively associated with female gender, being single, having children, living with a person aged 60 years or older (6), lower education level, working in a critical care unit (7). In addition, it is negatively associated with self-efficacy, resilience, as well as intra and extra-family social support (8). Additionally, the anxiety of nurses is positively associated with female gender, being single, having workload increased (6), working in a critical care unit (7), being suspected with COVID-19 infection, 
insufficient personal protective equipment (9) and negatively with higher self-efficacy, resilience, intra and extra-family social support (8). Meanwhile, their symptoms of stress have been positively associated with female gender, aged $\leq$ years, watching or reading COVID-19 news $\geq$ two hours per day, poor family and social support (10), fear of infection, fear transmission to the family member. Furthermore, it has been negatively associated with having training courses on COVID-19, availability of personal protective equipment and obtaining special attention from hospital administration (11).

Psychological intervention for those at higher risk of common mental health problems should be an integral part of work plans suggested in fighting the outbreak (12). The wide range of risk factors and comorbidities of nurses which increase their burden of common mental health problems necessitates special attention, prevention and intervention.

The Systematic Review by Al Maqbali et al. (2021) included studies that were mainly conducted in China (5). The paucity of related evidence from Indonesia was a predisposition for this study which aims to assess the rate of depression, anxiety and stress and their related risk factors among nurses working during the COVID-19 pandemic in Indonesia.

\section{Methods}

\section{Study design and Participants}

This cross-sectional study was carried out from 20th July to 19th August 2020 among nurses working in a provincial COVID-19referral hospital in Indonesia. A total of 745 nurses working in clinical settings were invited to the study via private message or social media groups. However, only 491 responded and completed the online questionnaires (response rate of $65.9 \%$ ).

\section{Measures}

Data was collected using google form consisting of questions on socio-demographic information such as age, gender, latest education, employment status, duration of employment, marital status, including questions on whether they had any financial hardship during the COVID-19pandemic and on their experience of social rejection, either by the family or the neighbors because of working in the hospital during COVID-19pandemic.

Furthermore, the presence of depression, anxiety and stress was measured using the Depression Anxiety Stress Scale (DASS-21) which is a 21 items self-report scale measuring characteristic attitudes and symptoms of depression, anxiety and stress (13). These 21 items were divided into each of seven items for depression, anxiety and stress, with each item been scored on a 4-point Likert scale $(0=$ did not apply to me at all, to $3=$ applied to me very much, or most of the time. In order to obtain a similar comparison with the original DASS-42, the DASS-21 scores were multiplied by two.

For depression scale, the scores of 9 or less, $10-13,14-20,21-27$ and 28 or greater were considered "normal", "mild", "moderate", "severe" and "extremely severe", respectively. For anxiety scale, scores of 7 or 
less, 8-9, 10-14, 15-19 and 20 or greater were considered "normal", "mild", "moderate", "severe" and "extremely severe", respectively. In addition, for stress scale, scores of 14 or less, 15-18, 19-25, 26-33 and 34 or greater were considered "normal", "mild", "moderate", "severe" and "extremely severe", respectively (13).

The DASS-21 is an easy-to-use screening instrument which is reliable and has been well utilized globally. Furthermore, it has been translated into various languages and has high reliability (14-17). In this study, the overall reliability coefficient (Cronbach alpha) of DASS-21 scale used was 0.94 , while for each subscale was $0.84,0.86$ and 0.86 for depression, anxiety and stress, respectively.

\section{Statistical analysis}

The socio-demographic variables such as gender, age group, marital status and education were presented in number and percentage. Chi-squared test was used in testing the association between the sociodemographic and the presence of moderate to extremely severe mental distress. Furthermore, the normal distribution of numerical data and the correlation between numerical variables were tested using the Shapiro-Wilk and Spearman correlation tests, respectively. The association between socio-demographic variables and the DASS- 21 scores was examined using the Mann Whitney $U$ test while, multiple logistic analysis was performed to detect factors associated with the presence of depression, anxiety and stress. In addition, data analysis was carried out using the STATA 13 software.

\section{Results}

In this study, out of the 419 nurses that participated, majority were female $(72.5 \%)$, married $(75.4 \%)$, had been working in the hospital for 10 years or less (75.6\%), non-permanent staff (61.7\%) and more than half were aged between 31 to 56 years (55\%) with nursing diploma level of education (57.8\%). Table 1 shows the different demographic characteristics between regular and COVID-19nurses. 
Table 1

Difference of demographic and mental problem between COVID-19nurses and regular nurses $(n=491)$

\begin{tabular}{|lllllll} 
No & Characteristics & $\begin{array}{l}\text { Total } \mathbf{n} \\
(\%)\end{array}$ & $\begin{array}{l}\text { CoVID-19Nurses, } \mathbf{n} \\
(\%)\end{array}$ & $\begin{array}{l}\text { Regular nurses, } \mathbf{n} \\
(\%)\end{array}$ & $\mathbf{x 2}$ & $\begin{array}{l}\text { P- } \\
\text { value }\end{array}$ \\
\hline 1 & Gender & & & & & \\
\hline & Male & $\begin{array}{l}135 \\
(27.5)\end{array}$ & $45(45.5)$ & $90(22.9)$ & 20.1 & 0.001 \\
& Female & $\begin{array}{l}356 \\
(72.5)\end{array}$ & $54(54.5)$ & $302(77.1)$ & & \\
& & & & & \\
\end{tabular}

2 Age group

$\begin{array}{llllll}22-30 & 221(45) & 53(53.5) & 168(42.8) & 3.64 & 0.056 \\ 31-56 & 270(55) & 46(46.5) & 224(57.2) & & \end{array}$

3 Education

$\begin{array}{llllll}\text { Nursing Diploma } & 284 & 63(63.6) & 221(56.4) & 1.7 & 0.191\end{array}$

$\begin{array}{llll}\text { Bachelor of } & 207 & 36(36.4) & 171(43.6) \\ \text { Nursing } & (42.2) & \end{array}$

4 Employment status

$\begin{array}{lllcll}\text { Non-permanent } & \begin{array}{l}303 \\ (61.7)\end{array} & 75(75.8) & 228(58.2) & 10.35 & 0.001 \\ \text { Permanent } & \begin{array}{l}188 \\ (38.3)\end{array} & 24(24.2) & 164(41.8) & & \\ & & & & \end{array}$

$5 \quad$ Employment duration

$\begin{array}{lllcll}\leq 10 \text { years } & \begin{array}{l}371 \\ (75.6)\end{array} & 86(86.8) & 285(72.7) & 8.58 & 0.003 \\ & & & & & \\ \geq 11 \text { years } & 120 & 13(13.2) & 107(27.3) & \\ & (24.4) & & & \end{array}$

$6 \quad$ Marital Status

$\begin{array}{lllcll}\text { Unmarried } & 121 & 29(29.3) & 92(23.5) & 1.44 & 0.23 \\ & (24.6) & & & & \\ \text { Married } & 370 & 70(70.7) & 300(76.5) & \\ & (75.4) & & & \end{array}$

7 Any financial problem during COVID-19pandemic

$\begin{array}{llllll}\text { No } & 159 & 27(27.2) & 132(33.7) & 1.67 & 0.22 \\ (32.4) & & & & \end{array}$




\begin{tabular}{|c|c|c|c|c|c|c|}
\hline No & Characteristics & $\begin{array}{l}\text { Total n } \\
\text { (\%) }\end{array}$ & $\begin{array}{l}\text { COVID-19Nurses, } n \\
\text { (\%) }\end{array}$ & $\begin{array}{l}\text { Regular nurses, } n \\
\text { (\%) }\end{array}$ & $x 2$ & $\begin{array}{l}\mathrm{P} \text { - } \\
\text { value }\end{array}$ \\
\hline & Yes, getting worst & $\begin{array}{l}332 \\
(67.6)\end{array}$ & $72(72.7)$ & $260(66.3)$ & & \\
\hline \multirow[t]{3}{*}{7} & Depression & & & & & \\
\hline & Yes & $42(8.5)$ & $10(10.1)$ & $32(8.2)$ & 0.37 & 0.53 \\
\hline & No & $\begin{array}{l}449 \\
(91.5)\end{array}$ & 89 (89.9) & $360(91.8)$ & & \\
\hline \multirow[t]{3}{*}{8} & Anxiety & & & & & \\
\hline & Yes & $\begin{array}{l}101 \\
(20.6)\end{array}$ & $14(14.1)$ & $87(22.2)$ & 3.13 & 0.07 \\
\hline & No & $\begin{array}{l}390 \\
(79.4)\end{array}$ & $85(85.8)$ & $305(77.8)$ & & \\
\hline \multirow[t]{3}{*}{9} & Stress & & & & & \\
\hline & Yes & $31(6.3)$ & $5(5.1)$ & $26(6.6)$ & 0.33 & 0.56 \\
\hline & No & $\begin{array}{l}460 \\
(93.7)\end{array}$ & $94(94.9)$ & $366(93.4)$ & & \\
\hline
\end{tabular}

\section{The prevalence of depression, anxiety and stress}

The prevalence of moderate to extremely severe depression, anxiety and stress among nurses were $8.7 \%$, $20.7 \%$ and $5.8 \%$, respectively, indicating that no difference of the rates was discovered between the COVID-19nurses and the regular nurses $(P>.05)$. However, the nurses that faced financial problems from the pandemic had a significantly higher rate of these mental distress, with $10.5 \%, 23.5 \%$ and $8.1 \%$ for depression, anxiety and stress $(P<.05)$, respectively. Further statistical analysis also confirms the poor association between demographic characteristics and depression, anxiety and stress $(P<.05)$, except for having financial hardship from the pandemic. Table 2 shows the details of the relationship between the DASS-21 scores and the socio-demographic characteristics. 
Table 2

Relationship between DASS-21 score and nurses' socio demographic characteristics

\begin{tabular}{|c|c|c|c|}
\hline Variable & Depression & Anxiety & Stress \\
\hline \multicolumn{4}{|l|}{ Gender } \\
\hline Male & $U=-0.67$ & $U=1.43$ & $U=1.18$ \\
\hline Female & $P=0.49$ & $P=0.15$ & $P=0.23$ \\
\hline \multicolumn{4}{|l|}{ Age } \\
\hline $22-30$ & $U=0.34$ & $U=0.91$ & $U=0.30$ \\
\hline $31-56$ & $P=0.73$ & $P=0.36$ & $P=0.75$ \\
\hline \multicolumn{4}{|l|}{ Education } \\
\hline Nursing Diploma & $U=0.45$ & $U=0.23$ & $U=0.09$ \\
\hline Bachelor of Nursing & $P=0.65$ & $P=0.81$ & $P=0.92$ \\
\hline \multicolumn{4}{|l|}{ Employment status } \\
\hline Non-permanent & $U=-1.31$ & $U=-1.25$ & $U=-1.19$ \\
\hline Permanent & $P=0.18$ & $P=0.20$ & $P=0.23$ \\
\hline \multicolumn{4}{|l|}{ Employment duration } \\
\hline$\leq 10$ years & $U=0.08$ & $U=0.96$ & $U=0.98$ \\
\hline$\geq 11$ years & $P=0.92$ & $P=0.33$ & $P=0.32$ \\
\hline \multicolumn{4}{|l|}{ Marital Status } \\
\hline Unmarried & $U=-0.08$ & $U=0.41$ & $U=-0.034$ \\
\hline Married & $P=0.93$ & $P=0.67$ & $P=0.97$ \\
\hline \multicolumn{4}{|c|}{ Any financial problem during COVID-19pandemic } \\
\hline No & $U=-2.86$ & $U=-2.8$ & $U=-3.48$ \\
\hline Yes, getting worst & $P=0.004$ & $P=0.004$ & $P=0.001$ \\
\hline \multicolumn{4}{|l|}{ Working Place } \\
\hline COVID-19ward & $U=0.75$ & $U=2.37$ & $U=0.64$ \\
\hline Non-COVID-19nursing ward & $P=0.44$ & $P=0.01$ & $P=0.52$ \\
\hline \multicolumn{4}{|l|}{ Have children } \\
\hline No & $U=-0.17$ & $U=0.17$ & $U=-0.10$ \\
\hline
\end{tabular}




\begin{tabular}{|llll|}
\hline Variable & Depression & Anxiety & Stress \\
\hline Yes & $P=0.86$ & $P=0.85$ & $P=0.91$ \\
\hline
\end{tabular}

\section{Associated risk factors of depression, anxiety and stress}

From the regression analysis, it was discovered that depression was associated with various factors i.e. the variable of having a positive attitude that the government may win against COVID-19(AOR $=0.39 ; 95 \%$ Cl: $0.19-0.81)$ and appropriate behavior by wearing a face mask whenever they leave their homes (AOR = 0.06 ; 95\% Cl: 0.008-047) were protective against depression $(P<.05)$. Meanwhile, the nurses that experienced social rejection by the family because of working in the hospital during the pandemic had approximately 3 times odd and those that received rejection by the neighbors had 5 times odd of having depression. In addition, those that frequently watched the news on TV about COVID-19which made them anxious, had approximately 3 times odd of having depression.

Furthermore, the presence of anxiety was discovered to be associated with various factors i.e. those that went to crowded places such as the market in the last few days, feeling worried about the pandemic, experienced rejections because of working in the hospital, either by family or neighbors. In addition, those that repeatedly watched the news about COVID-19on TV which made them anxious, were all having higher odds of suffering from anxiety symptoms $(P<.05)$. Conversely, being part of COVID-19nursing team was protective against anxiety ( $\mathrm{AOR}=0.36 ; 95 \% \mathrm{Cl}$ : $0.17-0.75)$.

Lastly, being a permanent hospital nurse staff had almost 4 times odd of suffering from stress while, experienced rejection by the family because of working in the hospital had almost 6 times odd of suffering from the stress $(P<.05)$. Table 3 shows the detail of multiple regression analysis for the risk factors of depression, anxiety and stress among nurses. 
Table 3

Multiple logistic regression for risk factors of Depression, Anxiety and Stress among Nurses

\begin{tabular}{|c|c|c|c|c|}
\hline Variable & AOR & SE & $\begin{array}{l}\mathrm{P}- \\
\text { value }\end{array}$ & $95 \% \mathrm{Cl}$ \\
\hline \multicolumn{5}{|l|}{ Depression } \\
\hline Sure, that the government can win against COVID-19 & 0.39 & 0.14 & 0.013 & $\begin{array}{l}0.19- \\
0.81\end{array}$ \\
\hline Wearing mask whenever going out from home & 0.06 & 0.06 & 0.007 & $\begin{array}{l}0.008- \\
0.47\end{array}$ \\
\hline Rejection by the family because of working in the hospital & 3.06 & 1.52 & 0.025 & $\begin{array}{l}1.15- \\
8.13\end{array}$ \\
\hline Rejection by the neighbours because of working in the hospital & 5.05 & 2.4 & 0.001 & $\begin{array}{l}1.99- \\
12.83\end{array}$ \\
\hline $\begin{array}{l}\text { Repeated and frequent news about COVID-19in the TV made you } \\
\text { anxious }\end{array}$ & 2.98 & 1.4 & 0.02 & $\begin{array}{l}1.18- \\
7.50\end{array}$ \\
\hline \multicolumn{5}{|l|}{ Anxiety } \\
\hline Being part of COVID-19nursing team & 0.36 & 0.13 & 0.006 & $\begin{array}{l}0.17- \\
0.75\end{array}$ \\
\hline Went to crowded places in last few days & 1.88 & 0.45 & 0.008 & $\begin{array}{l}1.17- \\
3.02\end{array}$ \\
\hline Feeling worried about the COVID-19pandemic & 3.57 & 2.04 & 0.026 & $\begin{array}{l}1.16- \\
10.95\end{array}$ \\
\hline Rejection by the neighbours because of working in the hospital & 5.43 & 1.78 & 0.001 & $\begin{array}{l}2.85- \\
10.33\end{array}$ \\
\hline $\begin{array}{l}\text { Repeated and frequent news about COVID-19in the TV made you } \\
\text { anxious }\end{array}$ & 1.99 & 0.59 & 0.02 & $\begin{array}{l}1.11- \\
3.57\end{array}$ \\
\hline \multicolumn{5}{|l|}{ Stress } \\
\hline Being permanent staff of the hospital & 3.86 & 2.13 & 0.01 & $\begin{array}{l}1.31- \\
11.38\end{array}$ \\
\hline Rejection by the family because of working in the hospital & 5.97 & 2.52 & 0.001 & $\begin{array}{l}2.60- \\
13.66\end{array}$ \\
\hline
\end{tabular}

\section{Discussion}

This study reveals several significant results regarding the burden felt by the nurses due to mental health stress and its associated factors. In this study, the rates $8.7 \%, 20.7 \%$ and $5.8 \%$, for moderate to extremely 
severe depression, anxiety and stress, respectively were discovered to be significantly lower compared to the pooled rates reported in a recent systematic review and meta-analysis (5). The fact that the participants in this study had been exposed to various information on COVID-19, including participating in awareness-raising campaign and having training courses, might be responsible for the lower rates of the mental problem discovered in this population. It has been discovered that obtaining courses related to COVID-19 is protective against mental distress (18). Therefore, providing relevant information to nurses about COVID-19 should be an integral part of the intervention program.

Another significant result of this study is the higher rate of depression, anxiety and stress experienced among nurses with financial hardship during the pandemic. Financial hardship experienced during the pandemic has been widely reported, either in general population $(19,20)$, students or adolescents $(21)$ or patients with chronic illness $(22,23)$. This hardship was felt the most among nurses during the implementation of the lockdown policy by the government. The reason for this financial hardship has been not well understood however, a possible explanation is that a decrease in the number of patient's visit to the hospital may decrease the income from nursing action incentive for the nurses. After all, a large number of nurses $(67.6 \%)$ that perceived that their financial status was getting worse during the pandemic called for further investigations.

It was discovered that social rejection by family and neighbors because of working in the referral hospital during the pandemic is a risk factor for depression and anxiety. In fact, the symptoms of depression and anxiety among Frontline nurses were lowered by intra and extra family social support (8). The rejection in this study population happened during the beginning of the outbreak, when the general population was unsure about the cause, prevention and treatment of the disease. With the passage of time, this rejection decreased due to the increase in understanding and awareness of the public about the disease.

Repeatedly watching COVID-19 related news on TV which makes the nurses anxious about the situation also independently contribute toward the presence of depression and anxiety. Such results have been reported earlier, where watching news related to the pandemic for more than two hours per day was associated with a high likelihood of depression and anxiety (10). Furthermore, it has been discovered that the effect of media vicarious traumatization between media exposure and anxiety is positive and significant (24). Nevertheless, the nature cross-sectional design of this study may not imply a temporal relationship between watching COVID-19 related news and mental distress. The result of this study calls for further investigation on the impact of COVID-19 news related content toward mental distress of the population.

With regards to the protective factors, being a part of the COVID-19 nursing team allow nurses obtain more adequate information about the pandemic. Meanwhile, the positive attitude that government may win the battle against COVID-19 improves the self-esteem of this nurses. High self-esteem is associated with a lower rate of depression and anxiety (25).

Furthermore, appropriate behavior by wearing a face mask when going out of the home increases confidence among the nurses therefore, lowering the feeling of depression faced during the pandemic 
(26). Having a positive attitude about COVID-19 should be promoted while, wearing a mask anytime necessary should be maintained and recommended not only to nurses, but also to other healthcare workers and the general population.

\section{Conclusion}

The nurses that work at the frontline of the COVID pandemic experience mental distress albeit at different levels. This study shows that those with financial hardship have a higher rate of mental distress, while positive attitude and healthy behavior are protective. In clinical practice, nurses working with COVID-19 patients should obtain adequate social support, not only from fellow nurses and healthcare workers but also the family and neighbors. Whenever possible, providing the nurses financial subsidiary is encouraged as it could buffer them from financial uncertainty during the pandemic.

\section{Declarations}

\section{Ethics approval and consent to participate}

All methods were carried out in accordance with relevant guidelines and regulations' and was approved by the ethics committee of the Faculty of Medicine of Universitas Syiah Kuala - Zainoel Abidin General Hospital, reference number 096/EA/FK-RSUDZA/2020. All respondents provided written informed consent for participation.

\section{Consent for publication}

Not applicable

\section{Availability of data and materials}

The datasets analyzed in this study are available from the corresponding author on request.

\section{Competing interests}

Nothing to declare

\section{Funding}

The work was supported by an award grant to Dr. Marthoenis by the Institute for Research and Community Services (LPPM), Universitas Syiah Kuala. The funding source has no implications on the conduct and the result reported in this study.

\section{Authors' contributions}

All authors designed the study, MR and LF led data collection and data analysis. MS prepared the first draft of the manuscript. JN completed and submitted the manuscript. All authors read and approved the 
manuscript prior to submission.

\section{Acknowledgements}

We would like to thank all the nurses in Zainoel Abidin Hospital for their participation in this study.

\section{Limitations}

This study has several limitations. First, the cross-sectional design could not infer the causation between the independent and outcome variables. Second, the study was conducted only in a general hospital, thus could not represent the nurse's condition in other provinces or settings. Third, the self-selection bias could also contribute to the limited generality of study results. Future studies therefore should consider using a longitudinal design, multiple settings and a higher response rate.

\section{References}

1. Jahrami H, BaHammam AS, AlGahtani H, Ebrahim A, Faris MAl, AlEid K, et al. The examination of sleep quality for frontline healthcare workers during the outbreak of COVID-19. Sleep Breath. 2020;2019.

2. Tu ZH, He JW, Zhou N. Sleep quality and mood symptoms in conscripted frontline nurse in Wuhan, China during COVID-19 outbreak: A cross-sectional study. Medicine (Baltimore). 2020;99(26):e20769.

3. Sampaio F, Sequeira C, Teixeira L. Nurses' Mental Health During the Covid-19 Outbreak: A CrossSectional Study. J Occup Environ Med. 2020;62(10):783-7.

4. Luceño-Moreno L, Talavera-Velasco B, García-Albuerne Y, Martín-García J. Symptoms of posttraumatic stress, anxiety, depression, levels of resilience and burnout in spanish health personnel during the COVID-19 pandemic. Int J Environ Res Public Health. 2020;17(15):1-29.

5. Al Maqbali M, Al Sinani M, Al-Lenjawi B. Prevalence of stress, depression, anxiety and sleep disturbance among nurses during the COVID-19 pandemic: A systematic review and meta-analysis. $J$ Psychosom Res [Internet]. 2021;141(September 2020):110343. Available from: https://doi.org/10.1016/j.jpsychores.2020.110343

6. Koksal E, Dost B, Terzi Ö, Ustun YB, Özdin S, Bilgin S. Evaluation of Depression and Anxiety Levels and Related Factors Among Operating Theater Workers During the Novel Coronavirus (COVID-19) Pandemic. J Perianesthesia Nurs. 2020;35(5):472-7.

7. Silwal M, Koirala D, Koirala S, Lamichhane A. “Depression, Anxiety and Stress among Nurses during Corona Lockdown in Hospital of Kaski, Nepal". J Heal Allied Sci [Internet]. 2020 Oct 19;10(2):82-7. Available from: https://www.jhas.org.np/jhas/index.php/jhas/article/view/210

8. Hu D, Kong Y, Li W, Han Q, Zhang X, Zhu LX, et al. Frontline Nurses' Burnout, Anxiety, Depression, and Fear Statuses and Their Associated Factors During the COVID-19 Outbreak in Wuhan, China: A BigScale Cross-Sectional Study. SSRN Electron J [Internet]. 2020;In Press. Available from: https://www.ssrn.com/abstract=3566144 
9. Pouralizadeh M, Bostani Z, Maroufizadeh S, Ghanbari A, Khoshbakht M, Alavi SA, et al. Anxiety and depression and the related factors in nurses of Guilan University of Medical Sciences hospitals during COVID-19: A web-based cross-sectional study. Int J Africa Nurs Sci [Internet]. 2020;13(May):100233. Available from: https://doi.org/10.1016/j.ijans.2020.100233

10. Arafa A, Mohammed Z, Mahmoud O, Elshazley M, Ewis A. Depressed, anxious, and stressed: What have healthcare workers on the frontlines in Egypt and Saudi Arabia experienced during the COVID19 pandemic? J Affect Disord [Internet]. 2021;278(May 2020):365-71. Available from: https://doi.org/10.1016/j.jad.2020.09.080

11. Hendy A, Abozeid A, Sallam G, Abboud Abdel Fattah H, Ahmed Abdelkader Reshia F. Predictive factors affecting stress among nurses providing care at COVID-19 isolation hospitals at Egypt. Nurs Open. 2021;8(1):498-505.

12. Liu $Y$, Chen $H$, Zhang N, Wang $X$, Fan $Q$, Zhang $Y$, et al. Anxiety and depression symptoms of medical staff under COVID-19 epidemic in China. J Affect Disord. 2021;278(April 2020):144-8.

13. Lovibond SH, Lovibond PF. Manual for the Depression Anxiety Stress Scales. Vol. 56, Psychology Foundation of Australia. 1995. 42 p.

14. Beiter R, Nash R, McCrady M, Rhoades D, Linscomb M, Clarahan M, et al. The prevalence and correlates of depression, anxiety, and stress in a sample of college students. J Affect Disord. 2015;173:90-6.

15. Bujang MA, Musa R, Liu WJ, Chew TF, Lim CTS, Morad Z. Depression, anxiety and stress among patients with dialysis and the association with quality of life. Asian J Psychiatr. 2015 Dec;18:49-52.

16. Bayram N, Bilgel N. The prevalence and socio-demographic correlations of depression, anxiety and stress among a group of university students. Soc Psychiatry Psychiatr Epidemiol. 2008;43(8):66772.

17. Zanon C, Brenner RE, Baptista MN, Vogel DL, Rubin M, Al-Darmaki FR, et al. Examining the Dimensionality, Reliability, and Invariance of the Depression, Anxiety, and Stress Scale-21 (DASS-21) Across Eight Countries. Assessment. 2020;

18. Zheng R, Zhou Y, Qiu M, Yan Y, Yue J, Yu L, et al. Prevalence and associated factors of depression, anxiety, and stress among Hubei pediatric nurses during COVID-19 pandemic. Compr Psychiatry [Internet]. 2021;104:152217. Available from: https://doi.org/10.1016/j.comppsych.2020.152217

19. Sultana MS, Khan AH, Hossain S, Islam T, Hasan MT, Ahmed HU, et al. The association between financial hardship and mental health difficulties among adult wage earners during the COVID-19 pandemic in Bangladesh: Findings from a cross-sectional analysis. 2020;0-2. Available from: https://psyarxiv.com/q3ehv/

20. Ahmed SAKS, Ajisola M, Azeem K, Bakibinga P, Chen Y-F, Choudhury NN, et al. Impact of the societal response to COVID-19 on access to healthcare for non-COVID-19 health issues in slum communities of Bangladesh, Kenya, Nigeria and Pakistan: results of pre-COVID and COVID-19 lockdown stakeholder engagements. BMJ Glob Heal. 2020;5(8):e003042. 
21. Kecojevic A, Basch $\mathrm{CH}$, Sullivan M, Davi NK. The impact of the COVID-19 epidemic on mental health of undergraduate students in New Jersey, cross-sectional study. PLoS One [Internet]. 2020;15(9 September):1-16. Available from: http://dx.doi.org/10.1371/journal.pone.0239696

22. Baddour K, Kudrick LD, Neopaney A, Sabik LM, Peddada SD, Nilsen ML, et al. Potential impact of the COVID-19 pandemic on financial toxicity in cancer survivors. Head Neck. 2020;42(6):1332-8.

23. Jammu AS, Chasen MR, Lofters AK, Bhargava R. Systematic rapid living review of the impact of the COVID-19 pandemic on cancer survivors: update to August 27, 2020. Support Care Cancer. 2020;

24. Liu C, Liu Y. Media exposure and anxiety during covid-19: The mediation effect of media vicarious traumatization. Int J Environ Res Public Health. 2020;17(13):1-15.

25. Sowislo JF, Orth U. Does low self-esteem predict depression and anxiety? A meta-analysis of longitudinal studies. Psychol Bull. 2013;

26. Wang C, Chudzicka-Czupała A, Grabowski D, Pan R, Adamus K, Wan X, et al. The Association Between Physical and Mental Health and Face Mask Use During the COVID-19 Pandemic: A Comparison of Two Countries With Different Views and Practices. Front Psychiatry. 2020;11(September):1-13. 